\title{
Forward - Green Virtual Enterprises and their Breeding Environments: Sustainable Manufacturing, Logistics \& Consumption
}

\author{
David Romero $^{1-2}$, Arturo Molina ${ }^{1}$ \\ ${ }^{1}$ Tecnológico de Monterrey, Mexico ${ }^{2}$ Griffith University, Australia \\ david.romero.diaz@gmail.com, armolina@itesm.mx
}

\begin{abstract}
Green Virtual Enterprise Breeding Environments and their ForwardGreen Virtual Enterprises, represent a promising paradigm to face the sustainable manufacturing, logistics and consumption challenges towards a Circular Economy. This paper explores the 'build-to-order supply chain management' paradigm and the customers involvement in sustainable supply chains to support the creation and operation of goal-oriented supply networks capable of responding to the two-sided market demands of the Circular Economy by means of sustainable offers by industry and sustainable demand by society.
\end{abstract}

Keywords: Collaborative Networked Organisations, Green Virtual Enterprises, Breeding Environments, Industrial Ecology, Sustainable Manufacturing, Sustainable Logistics, Sustainable Consumption, Circular Economy.

\section{Introduction}

Circular Economy $(C E)$ is a generic term for a new and more sustainable industrial economy in which material, energy and waste (MEW) flows are closed-loop [1] [2].

In a $C E$, two types of cyclic flows can be identified: a) quasi-cyclic flows in where there is a certain degree of cycling in resources circulation through an industrial system, which reduces the need for external resources input and waste output, and b) cyclic flows which have the highest degree of cycling (self-sufficiency) with closed-loop circulation of resources within an industrial system [1] [3].

Developing a $C E$ is about optimising industrial systems, and eco-industrial chain models are the prerequisite and basis for running eco-industrial systems [4] [5].

An Eco-Industrial Chain (EIC) refers to a closed-loop model of economic activities creating feedback cycles of resources $\rightarrow$ products $\rightarrow$ renewable resources, following the '3R' principles of the $C E$ (Reduce, Reuse, Recycle) in the processes of production, logistics and consumption in order to achieve eco-industrial systems with improved economic activities and environmental benefits [4] [5].

The ' $3 \mathrm{R}$ ' principles are at the core of the $C E$ development strategy: Reduce refers to the input of resources usage, aiming at reducing the input materials and energy in the production and consumption processes; Reuse is concerned with processing, and promotes a higher utilisation rate of resources by reusing raw materials, by-products and used-products, so products' lifecycle can be extended and the waste created in production processes can be minimised; finally, Recycle is concerned with output, which requires that waste be turned into secondary resources replacing virgin resources input [6]. 
Nevertheless, building a $C E$ in the industrial landscape is not enough, since consumerism can have a big impact on the environment and consume large amounts of energy. As a result, consumers in the marketplace play a crucial role to achieve a sustainable economy, since " $C E$ is not just about sustainable production models and products, but also about sustainable lifestyles and societies sustaining them" [7].

This research will explore Forward - Green Virtual Enterprises and their breeding environments [8] [9] within the 'build-to-order supply chain management' paradigm [10] in order to support the creation and operation of goal-oriented supply networks capable of responding to the two-sided market demands of the $C E$, sustainable offers by industry and sustainable demand by society.

\section{Green Virtual Enterprises and their Breeding Environments}

A Green Virtual Enterprise Breeding Environment $(G V B E)$ is a long-term strategic alliance of green enterprises ${ }^{1}$ and their related support institutions aimed at offering the necessary conditions (human, financial, social infrastructural and organisational) to support the rapid and fluid configuration of GVEs. From a 'socio-economic and technical' point of view, GVBEs support the creation of an adequate environment for the establishment of cooperation agreements, common operation principles, common interoperable infrastructures, common ontologies, and mutual trust among others, with the objective of preparing their members to collaborate in potential GVEs that will be established when a green business opportunity arises (e.g. identified by a GVBE member acting as a broker). From an 'ecological' perspective, GVBEs promote the sharing and recycling of resources such as information, materials, water, energy and/or infrastructure with the intention of achieving sustainable development in a collaborative way (e.g. industrial symbiosis ${ }^{2}$ ) [8] [9].

Green Virtual Enterprises (GVEs) are short-term and dynamic coalitions of green enterprises that may be tailored within a $G V B E$ to respond to a single cooperation opportunity, through integrating the green technology (skills or core-competences and resources) required to meet or exceed the quality, time and cost frames expected by the customer with a low ecological footprint, and that dissolve once their mission/goal has been accomplished, as whose cooperation is supported by computer networks [8] [9].

Depending on its delivery or recovery goal, a $G V E$ can be tailored to become a dynamic forward supply network for delivering new green products (virgin or used/ recovered) to the market, or a dynamic reverse supply network [12] for recovering the products sold under the GVBE brand (product stewardship) for service provisioning, product recovering or for safe disposal [8] [9].

${ }^{1}$ A Green Enterprise is an enterprise that strives to meet the triple bottom line by ensuring that all products, processes, manufacturing and logistics activities in its business operation address the sustainability principles [8] [9].

2 Industrial Symbiosis can be defined as an industrial ecology strategy based on collaboration and synergetic possibilities, aimed at sharing/exchanging information, materials, water, energy and/or infrastructure (e.g. services) among industrial actors in order to increase economic gains and achieve sustainable development in an eco-industrial network [2] [11]. 
GVEs as dynamic reverse supply networks $(R-G V E s)^{3}$ are temporary alliances of green enterprises that come together in order to better respond to a business opportunity based on a sustainable reverse logistics and end-of-life manufacturing approach for recovering products, parts, subassemblies and/or scrap through the most efficient use of their complementary skills or core-competences and shared resources for their direct-use (re-use), repair, refurbishment, re-manufacture, recycle or safe disposal within a $G V B E$.

In this research work, authors will focus on the case of GVEs as dynamic forward supply networks (F-GVEs) operating as temporary alliances of green enterprises that come together in order to better respond to the market demands through the most efficient use of their complementary skills or core-competences and shared resources, for developing and delivering in a sustainable way new products (goods and services) to the customer with a minimal environmental impact (see Fig. 1) [8] [9].

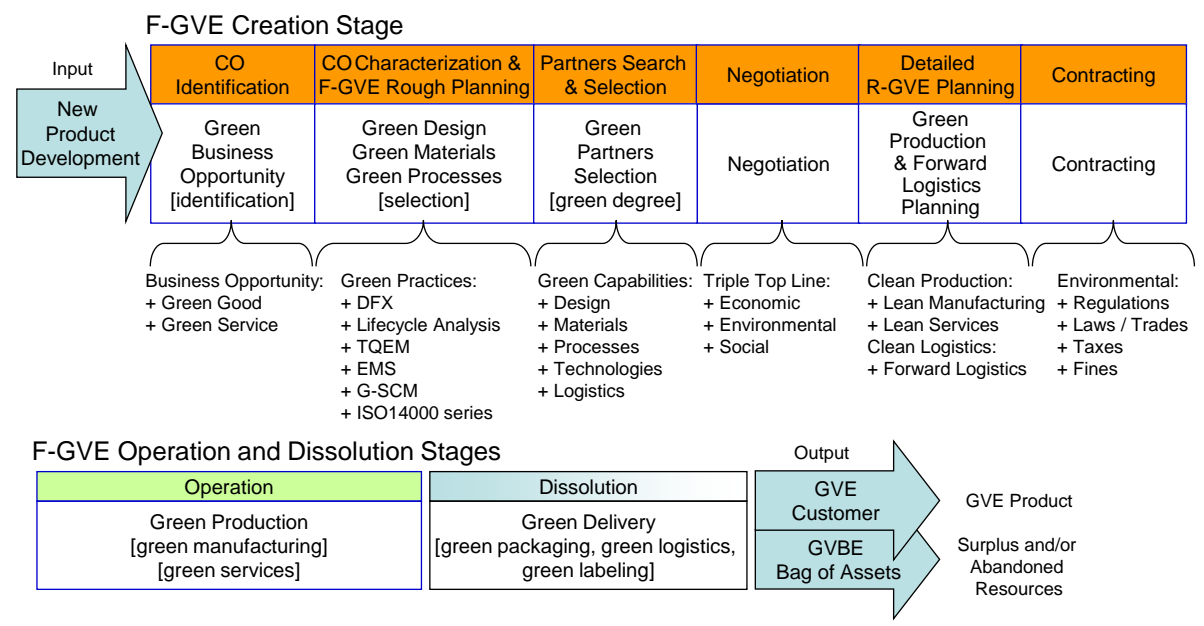

Fig.1. Forward Green Virtual Enterprise Lifecycle: Dynamic Forward Supply Network

Furthermore, F-GVEs can be sub-tailored to become Green Virtual Manufacturing Enterprises compromising different kinds of resources, manufacturing processes and knowledge needed for designing, engineering and manufacturing sustainable goods for the customer; Green Virtual Service Enterprises sharing knowledge and skills to fulfil different customer requests in after-sales services in a sustainable way; and Green Virtual Product-Service Enterprises integrating manufacturers and service providers in order to support a sustainable customer lifecycle based on a combination of sustainable goods and their related value added services (see Fig. 2).

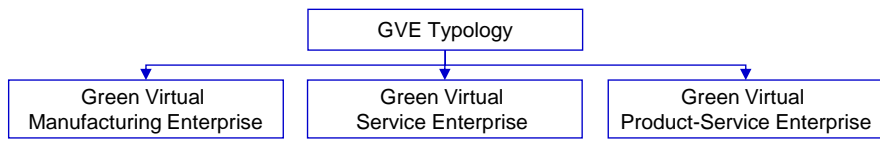

Fig.2. Forward Green Virtual Enterprise Typology

${ }^{3}$ For additional information on R-GVEs please refer to [12]. 


\section{Sustainable Manufacturing \& Logistics: Build-to-Order Supply Networks}

When judging the rationality of economic development in the past and looking into the future, if a sustainable economy is the goal, it is important to understand that the industry of the $21^{\text {st }}$ century will not be the same as the mass-production model throwaway economy of the $20^{\text {th }}$ century [7]. The emerging $C E$ will rely on new sustainable (mass-) customised products (goods and services) [13] and production and service provision models [14], as well as their related sustainable business models [15], to support (mass-) customisation, sustainable production and logistics and ondemand manufacturing/service provision as enablers of a sustainable industry: 'Delivering not what the market wants, but what specific customers want'... 'Producing green products just when the customer needs them and only in the quantity they are needed'.

Sustainable Manufacturing is defined as "a systems approach for the creation and distribution (supply chain) of innovative products (goods and services) that minimises resources utilisation (inputs such as: materials, energy, water, and land), eliminates toxic substances, and produces zero waste that in effect reduces greenhouse gases (carbon intensity), across the entire lifecycle of products" [16]. F-GVEs aim to bring forward an emerging sustainable manufacturing and logistics mode of operation focused on compromising high levels of customisation, high customer-driven design, volume flexibility (not quantity restricted), short-cycle time, zero-inventory costs, minimal total cost and high supply chain integration for offering and delivering green products to the market in a sustainable way [17].

$F$-GVEs focus on implementing mass-customisation and personalisation in a sustainable manufacturing and logistics paradigm empowering sustainability through eco-friendly and high flexible product designs (goods and/or services), production and/or service systems, and supply chains/networks.

The Build-to-Order (BTO) operation model [17] aims to incorporate the key advantages of different operation models to become an attractive sustainable strategy for manufacturing and service enterprises. The BTO model takes the characteristics of 'high level customisation' and 'customer driven design' of the Engineer-to-Order (ETO) model, the 'volume flexibility' of Make-to-Order (MTO) model, the 'shortcycle time' of the MTO and Assembly-to-Order (ATO) models, the 'zero-inventory costs' of the ETO model, the 'minimal total cost' of the Make-to-Stock (MTS) model, and the 'supply chain integration' of the Configure-to-Order (CTO) model towards more sustainable supply networks operations [17]. Nevertheless, the BTO model implementation challenges the capacity and capability of a single enterprise calling for a 'network of enterprises' to gain access to its sustainable benefits and competitive advantage. Therefore, F-GVEs and their breeding environments represent a wellsuited model to guarantee the agility, leanness, greenness, flexibility, collaboration and specialisation levels [9] needed to deploy the BTO model successfully (see Fig. 3).

A high level of customisation can be achieved by means of the F-GVE partners' green capabilities and capacities integration, thus avoiding design, engineering, manufacturing and/or logistics competence and/or resource restrictions to develop 
sustainable (mass-) customised products (goods and/or services) ${ }^{4}$ [17] [18]. F-GVEs will be always created with the most suitable GVBE members for fulfilling any special request of a green customer or for guaranteeing the requirements of a given green business opportunity [8] [9]. Moreover, (mass-) customisation offers the opportunity to develop true sustainable products (goods and services) with a high performance when it comes to meet the customer needs and being environmental-friendly within an affordable price [13].

High customer-driven design is in the nature of F-GVEs, being 'goal-oriented supply networks' driven by the aim of grasping a single green customer request or green business opportunity [17] [18]. F-GVEs are customer-oriented entities where a 'network of enterprises' focuses on a 'customer-centric collaboration' to co-create a green product (whether of the goods or services type) [19]. By avoiding or reducing the risks involved in forecasting the right production mix, $F$-GVEs can save a great number of resources (e.g. raw materials, energy, water, etc.) related to unsold products, and conserve also such input resources for a longer time till the moment they are truly needed (e.g. just-in-time) [8] [9].

Volume flexibility is satisfied by adding/aggregating F-GVE partners' production capacities and accommodating the proper volume of work accordingly to the task to their production capacity availability [17] [18]. Such flexibility allows a sustainable manufacturing where the required amount of products will be produced, and any waste related to unsold products be avoided (resources conservation) [8] [9].

Short-cycle time, or shortest-cycle time possible, is attained by the analysis of different $F-G V E$ partners topologies and work-breakdown-structure configurations during the F-GVE creation in order to create the right partnership and schedule (critical path) to meet or exceed the time-frame (lead time) expected by the green customer [17] [18]. F-GVE partners' search and selection process [20] [21] will guarantee always the best possible forward supply network configuration in terms of cost-efficiency, flexibility, responsiveness and lowest ecological footprint to manufacture and deliver a product [8] [9].

Zero-inventory costs are realised since F-GVEs don't need to have an inventory before any manufacturing order is launched [17] [18]; F-GVEs operate under an on-demand manufacturing/service provision paradigm which can be considered a resources conservation strategy [8] [9].

Minimal total cost is accomplished due to the cost savings gained throughout the forward supply network [17] [18] by means of selecting the most cost-effective $F-G V E$ partners for the manufacturing and logistics value added activities needed to be performed and efficient $F-G V E$ operation [8] [9].

A high supply chain integration is reached thanks to the GVBE role as long-term strategic network [17] concerned with facilitating the adoption of common operation principles and interoperable infrastructures in advance to improve communication, cooperation and coordination between GVBE members; when members are selected to become GVE partners, they will behave as an integrated whole, therefore enhancing their overall agility, flexibility and productivity to collaborate in a $F-G V E$ [8] [9].

${ }^{4}$ Sustainable (mass-) customised products can be defined as goods or services capable of fulfilling engineering and customers' requirements including environmental, economic and social constrains [13] 


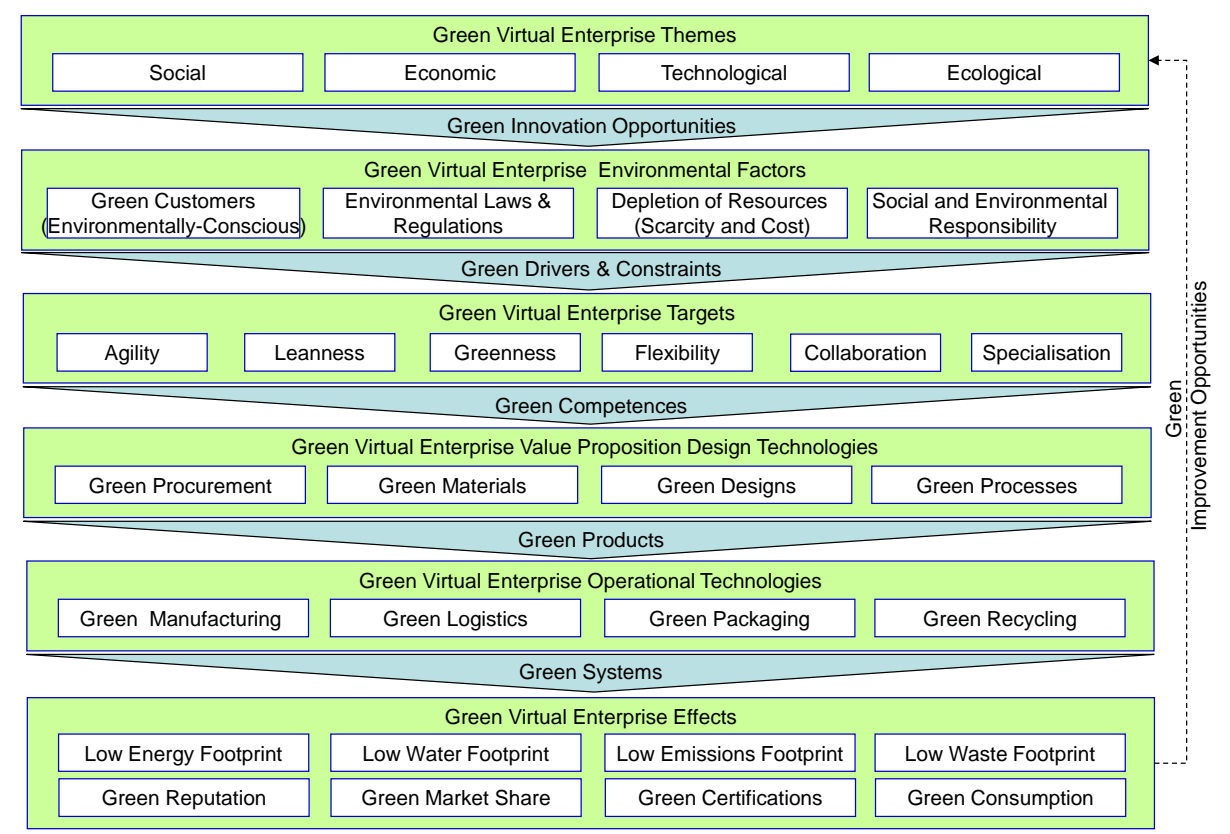

Fig.3. Forward Green Virtual Enterprise Vision-based Framework

\section{Sustainable Consumption: Customer Communities}

Sustainable Consumption is defined as "the consumption of goods and services that have a minimal impact upon the environment, are socially equitable and economically viable whilst meeting the basic needs of their target customers, without jeopardising the needs of future generations" [22].

Customers and, customer communities, play a vital role in contributing to a sustainable production and consumption in the industrial landscape and marketplace, being the ultimate target of a 'sustainable supply network'. Their involvement and empowerment in sustainable supply networks is of key importance for driving the demand for sustainable products (goods and services), since customers are those who initiate the creation of any given product. First, customers influence what goods and services are being produced and offered (e.g. green products), and partially how products are being produced, delivered and disposed (e.g. green manufacturing and logistics). Second, how products are being consumed, which drives or constrains any product lifecycle extension strategies (e.g. products with recycled materials, secondhand products, refurbished/ upgradable products, repaired products). Third, customers influence each other in their consumer decisions of what, how and how many products are consumed (e.g. green purchasing and usage recommendations).

Customers' role in sustainable production and consumption will continue growing in the coming years, as advances of the 'social' Internet empower green consumers to actively participate in different sustainable practices (e.g. recycling) [19] [23]. BTO supply networks [17] (e.g. GVEs and their breeding environments [8] [9]) offer the opportunity to meet green customers' demands and to manage their involvement 
in the co-creation/co-innovation [19] of sustainable (mass-) customised products [13] [14] and sustainable business models [15]. Sustainable (mass-) customisation may trade-off lead time for environmental-friendliness, but pays back the customer with a certain level of personalisation/customisation of his/her goods or services and a truly sustainable product lifecycle [13] [14].

In order to explore customers' role in achieving sustainable supply networks, authors have chosen Sarkis [24] framework for outlining the operational processes of a sustainable supply network with the customer involvement [adapted from 23]: Starting with green designing, customers education and awareness in (co-) designing and demanding sustainable products can incentivise manufacturing and service enterprises to look into more sustainable designs for their value propositions. This effect is also magnified by green (virtual) customer communities that collect, share and disseminate information about the sustainable performance of products, and customers increased interest to co-create/co-innovate sustainable products and business models [19]. Green procurement is the most obvious customer influence in a sustainable supply network since customers can choose their own goods manufacturers and service providers according to their sustainable performance (e.g. eco-certifications and environmental standards). Also, customers can influence procurement by eliminating and/or attenuating resources use by providing their own resources (e.g. self-service) and/or by helping to reuse or share resources (e.g. reuse programs) [23]. Green production and Green logistics are influenced by the customer consumption behaviour, which challenges manufacturing and service enterprises demand management, considering now the expected lead time by the customer in order to support sustainable production (e.g. dematerialisation, slow fashion, on-demand manufacturing/service provisioning, packaging reduction, product longevity) [25] and (collaborative) logistics practices (e.g. route planning, intermodal solutions, smart distribution, cargo consolidation, shared warehousing) [26]. Green purchasing, consumption and marketing, as the three main relationships of the firm with its customers, drives manufacturing and service enterprises to ethically promote their products (goods and/or services) by reinforcing customers' sustainable lifestyles using different sustainable marketing practices (e.g. rewards, discounts, eco-labels, demarketing, remarketing) in order to develop a mindful consumption mind-set [25]. Lastly, there is the green recycling achieved through different product recovery opportunities [12] that involve bringing back customers who have already purchased a product to restart a new supply network cycle presumably with greater efficiency and lower resources use (e.g. reuse, repair, refurbish, re-manufacture, recycle) [23] [25] (see Fig. 4).

\begin{tabular}{|c|c|}
\hline \multicolumn{3}{|c|}{ Sustainable Consumption } \\
\hline Buy Less & Share \\
& Gwap \\
\cline { 3 - 4 }
\end{tabular}

Fig.4. Green Customers Sustainable Consumption Profile

Increasingly, the sustainable production and consumption of products (goods and services) in the industrial landscape and marketplace will involve a mix of long- and short-term collaborative networks, strategic and goal-oriented networks [27], and networked enterprises and customers communities [19], making GVEs and their breeding environments [8] [9] a suitable collaborative environment and sustainable 
development model for customers' involvement and other stakeholders in the process of collaboratively creating new products in a sustainable way and meeting customers' needs and preferences.

\section{Sustainable Business Models: Interplay Networks}

A Sustainable Business Model is defined as "a business logic that seeks to create balanced social, environmental and economic value through integrating sustainability more fully into its business model and value proposition(s)" [28].

The development of sustainable business models architectures [15] is fundamental for the adoption of new sustainable production and consumption paradigms. In this sense, nowadays we can find some practical examples from an industrial perspective such as different product-service systems (PSS) variants aiming to deliver functionality rather than ownership through: 'product oriented approaches' based on maintenance and extended warranties; 'use-oriented approaches' based on rentals, leasing or sharing; and 'result-oriented approaches' based on pay per use or functional use; and various product recovery networks variants aiming to create new forms of value and/or capture the value missed in a product lifecycle based on reuse, repair, refurbish, re-manufacture and/or recycle strategies. From a customer perspective there are examples such as: self-service, do-it-yourself, co-design, co-creation and co-innovation. In both cases, these existing business models have further development opportunities for creating more sustainable industrial ecosystems and consumer markets. Understanding and supporting the growth of green networked enterprises and green customers' communities' interactions is a current challenge but a need towards a sustainable production and consumption [29] and a Circular Economy (see Table 1, Fig. 5, and [19]).

Table 1. A Business Model Framework for Sustainable Production \& Consumption

\begin{tabular}{|l|l|}
\hline Building Blocks & Description \\
\hline Value Proposition(s) & $\bullet$ Green Products $\bullet$ Green Services $\bullet$ Green Product-Service(s) \\
\hline Customer Segments & $\bullet$ Green Customers $\bullet$ Green Consumers $\bullet$ Green Communities \\
\hline Customer Relationships & $\bullet$ Green Purchasing $\bullet$ Green After-Sales Services \\
\hline Channels & $\bullet$ Green e-Marketplace $\bullet$ Green Brokers \\
\hline Key Partners & $\bullet$ Green Manufacturers $\bullet$ Green Service Providers • Green Brokers \\
\hline Key Activities \& Resources & $\bullet$ GVBE Management Systems $\bullet$ GVE Management Systems \\
\hline Cost Structure & $\bullet$ Green Costing Models (e.g. Green Loans, Green Taxes) \\
\hline Revenue Streams & $\bullet$ Green Profit Models (e.g. Green Market Share) \\
\hline
\end{tabular}

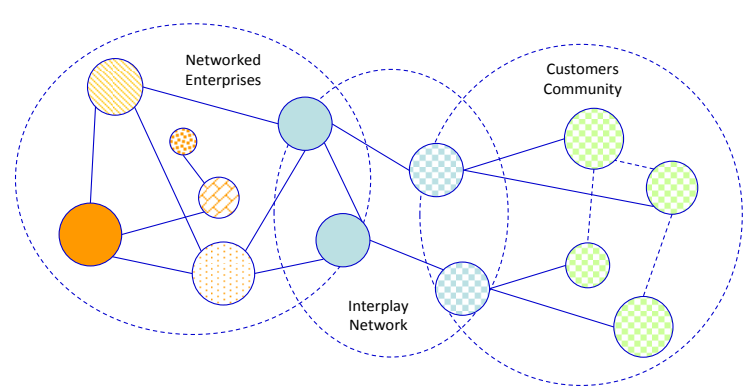

Fig.5. Interplay Networks as a base for Sustainable Production and Consumption 


\section{Conclusions \& Further Research}

Dynamic $F$-GVEs represent an intelligent integration of green enterprises' competences, best practices and technologies for creating and managing sustainable BTO supply networks in response to the development of sustainable (mass-) customised products.

GVEs and their breeding environments [8] [9] represent a promising collaborative environment for enhancing green enterprises and green-minded customers' readiness for collaboration in more sustainable industrial ecosystems and consumer markets needed for a true sustainable development [2].

A multitude of options exist for the development of more sustainable industrial ecosystems and consumer markets, but sustainability of such strategic options needs to be based on new sustainable business models in order to guarantee their success [15] [28], nevertheless this is a research are currently in a maturing stage.

Future research aims to refine the F-GVE - dynamic forward supply network model introduced, and the study, development and validation of its related business models for sustainable production and consumption.

Acknowledgments. The research presented in this document is a contribution for the ECOLEAD Project (FP6 IP 506958), for the S-MC-S Project (FP7 NMP-ICT-FoF 260090), and for the ITESM, Campus MTY \& CCM, Research Chairs.

\section{References}

1. Graedel, T.E.: Industrial Ecology: Definition and Implementation. In: Socolow, R. et al. (Eds.), Industrial Ecology and Global Change. Cambridge University Press, Cambridge, pp. 23-41 (1994)

2. Romero, D., Molina, A.: Green Virtual Enterprise Breeding Environments: A Sustainable Industrial Development Model for a Circular Economy. In: L.M. Camarinha-Matos et al. (Eds.): PRO-VE 2012, IFIP AICT 380, pp. 427-436 (2012)

3. Despeisse, M., Ball P.D., Evans, S., Levers, A.: Industrial Ecology at Factory Level A Conceptual Model. Journal of Cleaner Production 31(1), pp. 30-39 (2012)

4. Romero, D., Molina, A.: Towards a Sustainable Development Maturity Model for Green Virtual Enterprise Breeding Environments. 19th World Congress of the International Federation of Automatic Control (IFAC) (2014)

5. Guo, J., Cui, W.: Research on the Stability of Eco-Industry Chains. International Journal of Business and Management 5(11), pp. 152-155 (2010)

6. Shi, L., Yi, Q.: Strategy and Mechanism for Promotion of Circular Economy in China. In Chinese Journal of Population Resources and Environment 2(1), pp. 5-8 (2004)

7. Holemans, D.: Cities as Eco-Factories of the Future. Green European Journal, 6(1), pp. 4753 (2013)

8. Romero, D., Molina, A.: Green Virtual Enterprises and their Breeding Environments. In: L.M. Camarinha-Matos et al. (Eds.): PRO-VE 2010, IFIP AICT 336, pp. 25-35 (2010)

9. Romero, D., Molina, A.: Green Virtual Enterprises Breeding Environment Reference Framework. In: L.M. Camarinha-Matos et al. (Eds.): PRO-VE 2011, IFIP AICT 362, pp. 545-555 (2011)

10. Gunasekarana, A., Ngaib, E.W.T.: Build-to-Order Supply Chain Management: A Literature Review and Framework for Development. Journal of Operations Management, 23(5), pp. 423-451 (2005) 
11. Chertow, M.: Industrial Symbiosis. The Encyclopedia of Earth http://www.eoearth.org/article/Industrial_symbiosis

12. Romero, D., Molina, A.: Reverse - Green Virtual Enterprises and their Breeding Environments: Closed-Loop Networks. In: L.M. Camarinha-Matos and R.J. Scherer (Eds.): PRO-VE 2013, IFIP AICT 408, pp. 589-598 (2013)

13. Osorio, J., Romero, D., Betancur, M., Molina, A.: Design for Sustainable MassCustomization - Design Guidelines for Sustainable Mass-Customized Products. 20th International Conference on Engineering, Technology and Innovation (2014)

14. Bettoni, A., Corti, D., Canetta, L., Pedrazzoli, P., Taisch, M.: Integrated Product and Supply Chain Design: Bridging the Gap towards Networked Environment for Effective Implementation of a Sustainable Mass-Customized Solution. International Journal of Engineering, Science and Technology, 5(2), pp.65-78 (2013)

15. Short, S.W., Bocken, N.M.P., Rana, P., Evans, S.: Business Model Innovation for Embedding Sustainability - A Practice-Based Approach Introducing Business Model Archetypes. 10th Global Conference on Sustainable Manufacturing (2012)

16. Sudarsan, R.D. et al. (Eds.): Sustainable Manufacturing: Metrics, Standards, and Infrastructure -Workshop Report, NISTIR 7683 (2010)

17. Molina, A., Velandia, M, Galeano, N.: Virtual Enterprise Brokerage: A Structure-Driven Strategy to Achieve Build to Order Supply Chains. International Journal of Production Research 45(17), pp. 3853-3880 (2007)

18. Romero, D., Rabelo, R., Hincapié, M., Molina, A.: Next Generation Manufacturing Systems and the Virtual Enterprise. 13th IFAC Symposium on Information Control Problems in Manufacturing, pp. 634-641 (2009)

19. Romero, D., Molina, A.: Collaborative Networked Organisations and Customer Communities: Value Co-creation and Co-innovation in the Networking Era. Journal of Production Planning \& Control, 22(5-6), pp. 447-472 (2011)

20. Baldo, F., Rabelo, R., Vallejos, R.V.: An Ontology-based Approach for Selecting Performance Indicators for Partners Suggestion. In L. M. Camarinha-Matos (Eds.), PRO-VE 2007, IFIP AICT 243, pp. 187-196 (2007)

21. Wang, X., Wonga, T.N., Wang, G.: An Ontological Intelligent Agent Platform to Establish an Ecological Virtual Enterprise. Expert Systems with Applications, 39, pp. 7050-7061 (2012)

22. The Global Development Research Center (GDRC): Sustainable Consumption Definition. http://www.gdrc.org/sustdev/concepts/22-s-consume.html

23. Sigala, M.: Customer Involvement in Sustainable Supply Chain Management: A Research Framework and Implications in Tourism. Cornell Hospitality Quarterly, 55(1) pp.76-88 (2013)

24. Sarkis, A.: Strategic Decision Framework for Green Supply Chain Management. Journal of Cleaner Production, 11, pp. 397-409 (2003).

25. Sheth, J., Sethia N., Srinivas. S.: Mindful Consumption: A Customer-centric Approach to Sustainability. Journal of the Academy Marketing Science, 39, pp. 21-39 (2011)

26. Langley, J.: 7 Immutable Laws of Collaborative Logistics. NISTEVO Consulting (2000)

27. Camarinha-Matos, L.M., Ferrera, F., Oliveira, A.I.: Interplay of Collaborative Networks in Product Servicing. In: L.M. Camarinha-Matos and R.J. Scherer (Eds.): PRO-VE 2013, IFIP AICT 408, pp. 51-60 (2013)

28. Lüdeke-Freund, F.: Towards a Conceptual Framework of Business Models for Sustainability. Knowledge Collaboration \& Learning for Sustainable Innovation, Delft, The Netherlands (2010)

29. Romero, D., Cavalieri, S., Resta, B.: Green Virtual Enterprise Broker: Enabling Build-toOrder Supply Chains for Sustainable Customer-Driven Small Series Production. Advances in Production Management Systems Conference (2014) 